\title{
Atrophic Kidney-Like Lesion - Case Report of A Provisional Entity with Brief Review of Literature
}

\author{
Balamurugan THIRUNAVUKKARASU1 ${ }^{\mathbb{D}}$, Saket SINGH ${ }^{2} \mathbb{D}^{D}$, Aditya Prakash SHARMA ${ }^{2}$, Amanjit BAL ${ }^{1}$
}

Departments of 'Histopathology, and 'Urology, Post Graduate Institute of Medical Education \& Research (PGIMER), CHANDIGARH, INDIA

\section{ABSTRACT}

Atrophic kidney-like lesion is a recently recognized entity, post 2016 World Health Organization Classification of tumors of the urinary system. The behavior of this tumor is not fully known as only a handful of cases with limited follow-up are available. This entity closely mimics thyroid-like follicular carcinoma of the kidney, which has different prognosis.

We report a case of incidentally detected atrophic kidney-like lesion in an elderly gentleman who had urothelial carcinoma of the urinary bladder with a brief review of literature.

Atrophic kidney-like lesion and urothelial carcinoma of the urinary bladder association has not been reported in the literature.

Keywords: Atrophic kidney-like lesion, Thyroid-like follicular carcinoma, Kidney

\section{INTRODUCTION}

Atrophic kidney-like lesion (AKLL) is a recent entity described post 2016 World Health Organization (WHO) classification of tumors of the urinary system. With the available limited follow-up data, this is considered as a benign renal neoplasm with indolent behavior. Owing to its follicular architecture, it closely resembles thyroidlike follicular carcinoma of the kidney (TFRCC) (1). The distinction between the two is essential as the latter has chromosomal alterations in the form of gains and losses and an aggressive behavior with metastatic potential $(2,3)$.

\section{CASE REPORT}

A 71-year-old gentleman was a known case of recurrent low-grade urothelial carcinoma for 9 months for which he had undergone transurethral bladder tumor resection thrice. On routine surveillance, contrast enhanced computed tomography (CECT) abdomen showed a wellcircumscribed tumour measuring $2.6 \times 2.4 \mathrm{~cm}$ in the midthird region of the right kidney with focal extension into the upper pole. The kidney measured $5.5 \mathrm{~cm}$ in length with indistinct corticomedullary junction (Figure 1A,B). The patient underwent simple nephrectomy for the lesion. On gross examination, the renal capsule was intact, and the cut surface showed a well-demarcated tan brown lesion measuring $3 \times 2.8 \times 2.5 \mathrm{~cm}$ in the mid-third region. (Figure 1C). The renal sinus and ureter were unremarkable. On microscopy, the lesion was well demarcated from the

(Turk Patoloji Derg 2022, 38:148-152)

Received : 19.05.2021 Accepted : 06.06.2021 renal parenchyma by a thin fibrous capsule (Figure 2A). The lesion was composed of compact tubules lined by flattened and atrophic epithelium interspersed by cyst-like follicles. Many of the follicles were filled with pale to dense eosinophilic material detached from the epithelium (Figure 2B,C). The stroma between the follicles showed collagen deposition, few atrophic tubules, and capillaries. Focal amorphous calcific areas were also noted (Figure 2D). No atypical features like mitosis, necrosis or high nuclear grade areas were noted.

The differential diagnoses considered were atrophic kidney-like lesion, thyroid follicle-like renal cell carcinoma, metastatic follicular carcinoma of the thyroid, and welldifferentiated neuroendocrine tumour (carcinoid). A panel of immunohistochemistry was performed that included PAX8 (Cell Marque, RTU, clone MRQ-50), CK7 (Cell Marque, 1:300, clone OV-TL12/30), WT-1 (Dako, 1:50, clone 6F-H2), Synaptophysin (Cell Marque, 1: 200, Clone MRQ-40), CD117 (Dako, 1:500, clone A4502), and CD10 (Cell Marque, 1:30, clone 56C6). The cells were diffusely positive for PAX-8 (Figure 3A), and CK7 (Figure 3B), while negative for CD10 (Figure 3C), TTF-1 (Figure 3D), Synaptophysin, WT-1 and CD117. The renal sinus, pelvis and ureter were free. No extracapsular invasion was noted. Adjacent renal parenchyma showed preserved glomeruli and non-atrophic tubules. Based on morphology and immunophenotyping, an 'Atrophic kidney-like lesion' was diagnosed; Tumor stage - T1a; World Health Organization/

Correspondence: Amanjit BAL

Department of Histopathology, Postgraduate Institute of Medical Education and Research (PGIMER), CHANDIGARH, INDIA

E-mail: docaman5@hotmail.com Phone: +91 7087008134 

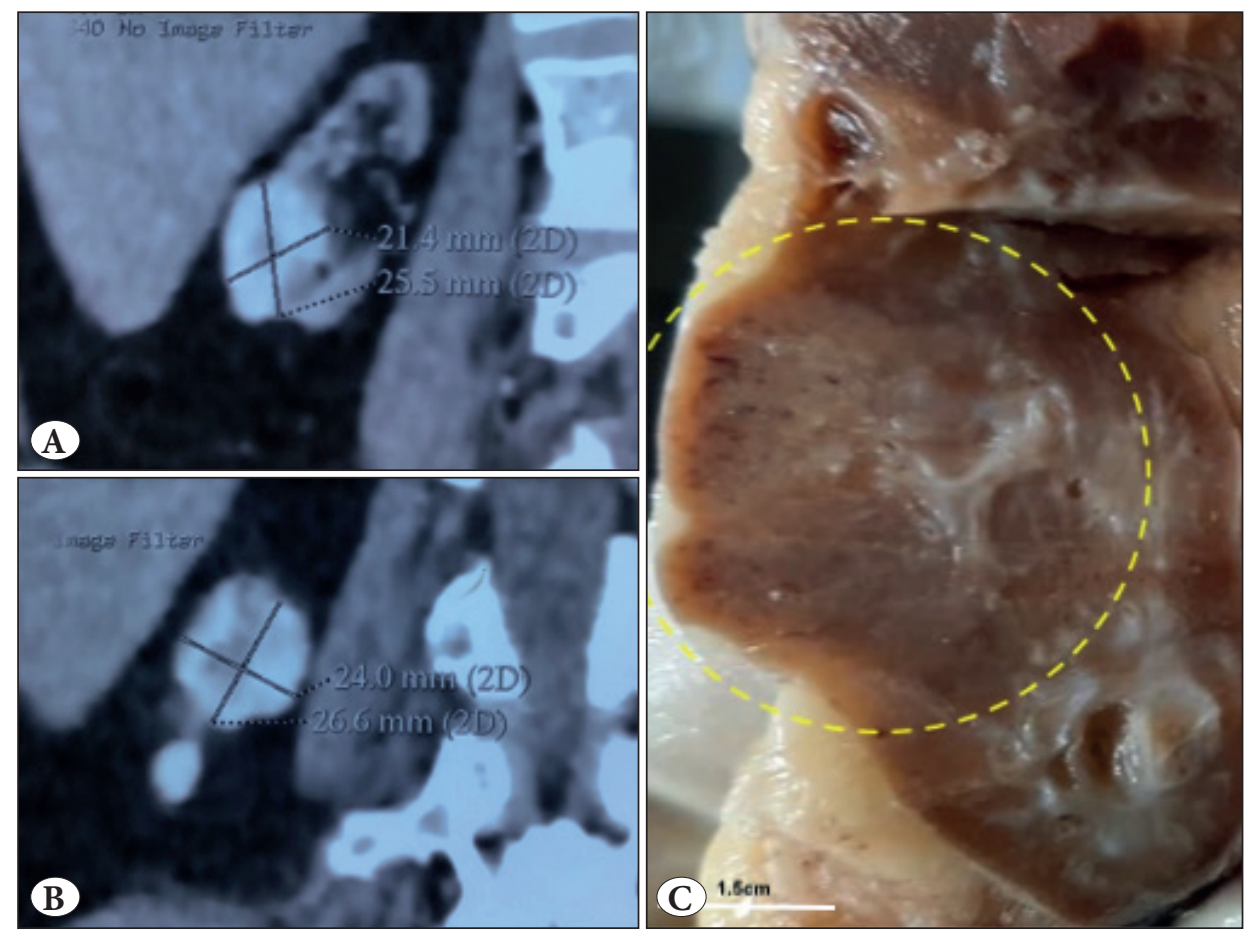

Figure 1: A, B) Contrast-enhanced CT abdomen showed a well-circumscribed tumour nodule in the upper pole in the background of a small kidney C) Cut surface shows a well-demarcated tan brown colored tumour measuring $3 \times 2.8 \times 2.5 \mathrm{~cm}$ in the mid-third region.
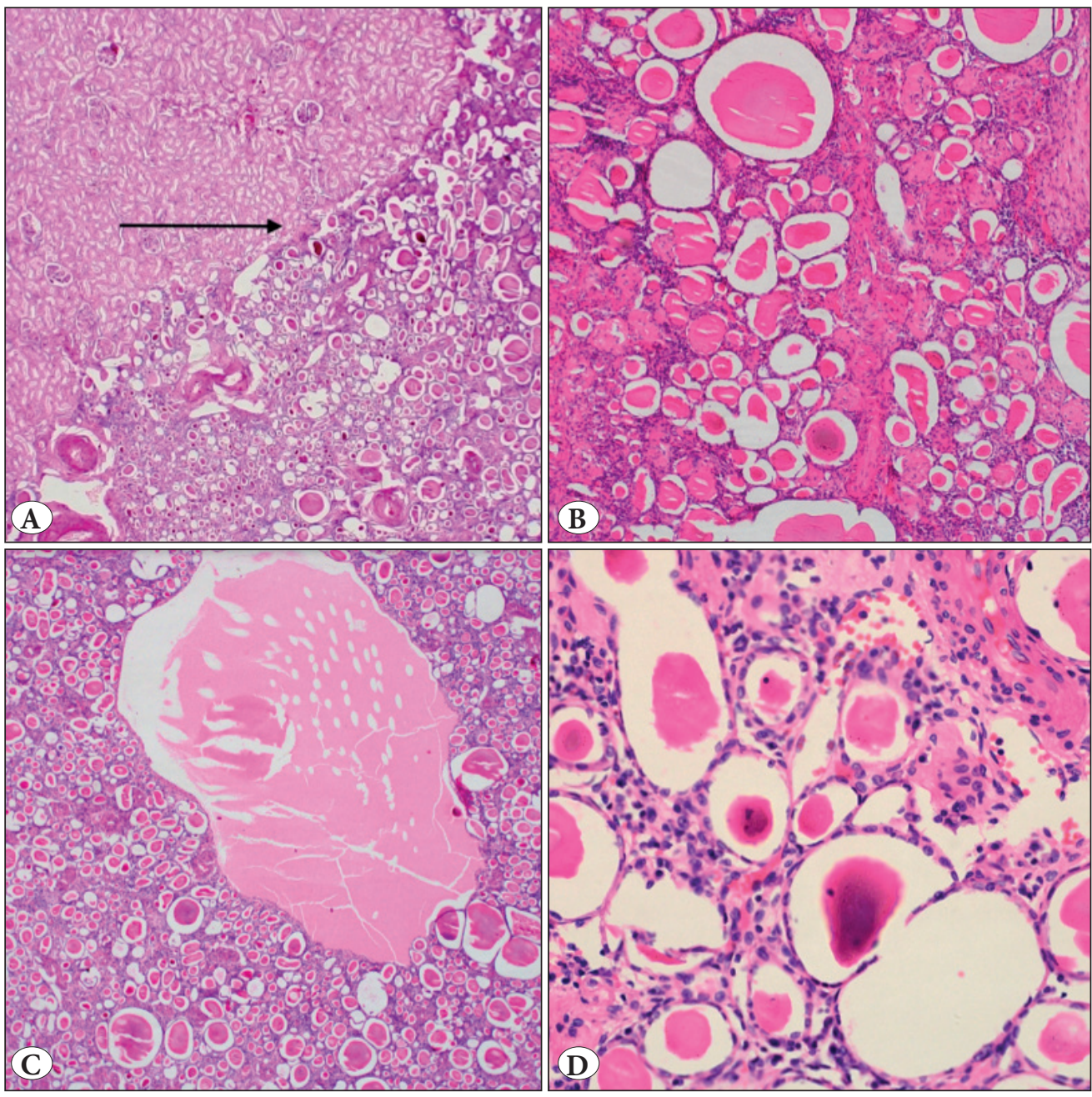

Figure 2: A) Tumour composed of multiple tightly packed varying sized follicles separated from native kidney by a thin capsule (arrow pointed) (H\&E, 40x) B) The follicles are filled with dense eosinophilic colloid-like secretions (H\&E, 100x) C) The lumen is filled with pink eosinophilic material and focal macrocystic degeneration (H\&E, 40x) D) The follicles are lined by flattened to cuboidal epithelium with occasional amphophilic calcific deposits (H\&E, 200x). 


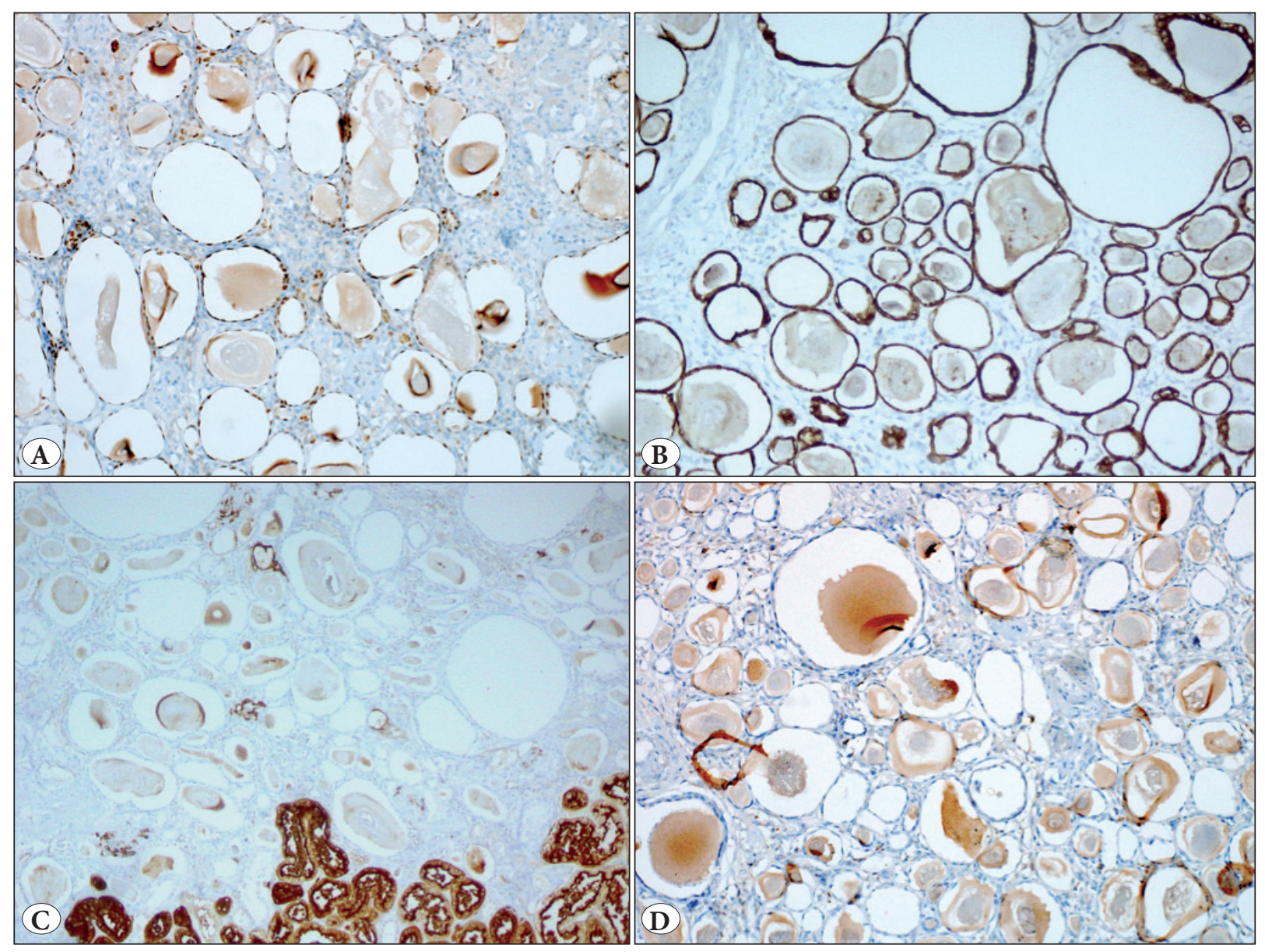

Figure 3: A) The tumour (follicular) cells are positive for PAX-8; B) CK7 Positive; C) CD10 Negative D) TTF-1 Negative (Immunoperoxidase, 200x)

International Society of Urological Pathology (WHO/ ISUP) Nuclear grade 1. There were no post-surgical complications. The patient has been on regular follow-up till date without any recurrence or distant metastasis.

\section{DISCUSSION}

The nomenclature "Atrophic kidney-like lesion (AKLL)" has been used interchangeably in the literature with "atrophic kidney-like tumour" and "atrophic kidney-like renal cell carcinoma" $(4,5)$. This was originally described by Hes et al in 2014 as a separate entity and its clonal nature was proven in a series of 3 cases (1). Atrophic kidneylike lesion was initially considered under Thyroid-like follicular carcinoma of the kidney (TFRCC) (5). Following the original description, many cases were reviewed and described as reports and case series, of which few were initially diagnosed as TFRCC $(6,7)$. The pathogenesis of AKLL is compared with that of glomerulocystic disease as the cells lining the cysts expressed WT-1, which is a marker of podocyte differentiation (8). At low power, both the tumors impart a follicular architecture. However, the distinguishing feature between AKLL and TFRCC can be appreciated on higher magnification. In TFRCC, the cells lining the follicles are cuboidal with abundant eosinophilic cytoplasm, high nuclear grade, and prominent nucleoli, resembling a proper follicular neoplasm of the thyroid whereas in AKLL the cells are flat/atrophic to low cuboidal $(9,10)$.

Distinction of atrophic kidney-like lesion from the end stage renal disease induced by chronic pyelonephritis is important. Chronic pyelonephritis with thyroidization also shows atrophic tubules with hyaline casts mimicking the neoplasm. The important distinguishing point is the presence of a well-defined capsule, lack of inflammation, and absence of glomeruli in-between the lesion. In the present case, the background renal parenchyma did not show features of chronic pyelonephritis. The differential diagnosis of AKLL includes metastatic follicular carcinoma of the thyroid, metanephric adenoma, multilocular cystic renal neoplasm of low malignant potential, and 
Table I: Published cases of atrophic kidney-like lesion in the literature

\begin{tabular}{lcccc}
\hline Author & Year & No. of cases & Age (yrs) & Comment \\
\hline Hes et al. (1) & 2014 & 3 & 31.3 (mean) & Monoclonal nature proved in one case \\
\hline Oshiro et al. (6) & 2014 & 1 & 19 & Bilateral tumors \\
\hline Berens et al. (7) & 2014 & 1 & 58 & Incidentally detected at autopsy \\
\hline Muscara et al. (10) & 2017 & 1 & 27 & Initially reported as TFRCC \\
\hline Herlitz et al. (8) & 2018 & 6 & 29 (mean) & Elucidation of pathogenesis akin to glomerulocystic kidney disease \\
\hline Amin et al. (9) & 2009 & 1 & 29 & One case initially reported as TFRCC \\
\hline Present case & 2021 & 1 & 71 & Incidentally detected post urothelial carcinoma of the bladder \\
\hline
\end{tabular}

TFRCC: Thyroid-like follicular carcinoma of the kidney

tubulocystic renal cell carcinoma (2,11). Metastatic follicular carcinoma of the thyroid shows TTF-1 expression, whereas metanephric adenoma shows tightly packed tubules lined by uniform cuboidal cells with occasional presence of papillary structures and diffuse positivity for WT1. Multilocular cystic renal neoplasm of low malignant potential shows cystic areas lined by clear cells positive for CD10. Tubulocystic renal cell carcinoma shows uniformly dilated cystic spaces intervened by fibrotic to hyalinized stroma. The cystic spaces are lined by cells with significant nuclear abnormalities and variable hobnailing.

To the best of our knowledge, 13 cases of AKLL have been reported in the English literature (Table I). Many of the cases were reviewed in the previously published cases of TFRCC. This lesion is usually reported in young patients with no major gender predilection. Age distribution of AKLL is from 9 to 58 years with a median age of 30.7 years. No specific genetic alterations have been reported yet (8). Classification of renal tumors is constantly evolving, and many new entities are being added and existing entities are being reclassified. Atrophic kidney-like lesion is a new entity with indolent behavior and described using different names. The Genitourinary Pathology Society (GUPS) has placed this lesion under "provisional entity" requiring more data for validation (4). The present case had thin well-defined capsule, occasional amorphous calcification with PAX8 and CK7 positivity. Features like high-grade nuclei, mitosis or necrosis were not seen. This index patient had completed treatment for recurrent low-grade papillary urothelial carcinoma of the urinary bladder and the renal lesion was incidentally detected on routine radiological surveillance. This association of AKLL with urothelial carcinoma has not been reported before.

\section{Conflict of Interest}

The authors declare no conflict of interest.

\section{Authorship Contributions}

All the authors were involved in conception and design of the work. $\mathbf{B M}$ and SS were involved in data collection and writing. $\mathbf{A B}$ and APS were involved in analysis of data and approval.

\section{REFERENCES}

1. Hes O, de Souza TG, Pivovarcikova K, Grossmann P, Martinek P, Kuroda N, Kacerovska D, Svajdler M, Straka L, Petersson F, Hora M, Michal M. Distinctive renal cell tumor simulating atrophic kidney with 2 types of microcalcifications. Report of 3 cases. Ann Diagn Pathol. 2014;18:82-8.

2. Jung SJ, Chung JI, Park SH, Ayala AG, Ro JY. Thyroid follicular carcinoma-like tumor of kidney: A case report with morphologic, immunohistochemical, and genetic analysis. Am J Surg Pathol. 2006;30:411-5.

3. Dong L, Huang J, Huang L, Shi O, Liu Q, Chen H, Xue W, Huang Y. Thyroid-like follicular carcinoma of the kidney in a patient with skull and meningeal metastasis: A unique case report and review of the literature. Medicine (Baltimore). 2016;95:e3314.

4. Trpkov K, Williamson SR, Gill AJ, Adeniran AJ, Agaimy A, Alaghehbandan R, Amin MB, Argani P, Chen YB, Cheng L, Epstein JI, Cheville JC, Comperat E, da Cunha IW, Gordetsky JB, Gupta S, He H, Hirsch MS, Humphrey PA, Kapur P, Kojima F, Lopez JI, Maclean F, Magi-Galluzzi C, McKenney JK, Mehra R, Menon S, Netto GJ, Przybycin CG, Rao P, Rao Q, Reuter VE, Saleeb RM, Shah RB, Smith SC, Tickoo S, Tretiakova MS, True L, Verkarre V, Wobker SE, Zhou M, Hes O. Novel, emerging and provisional renal entities: The Genitourinary Pathology Society (GUPS) update on renal neoplasia. Mod Pathol. 2021;34:1167-84.

5. Kuroda N, Hes O, Zhou M. New and emerging renal tumour entities. Diagn Histopathol 2016;22:47-56.

6. Oshiro Y, Hida AI, Tamiya S, Toyoshima S, Kuroda N, Hes O, Michal M. Bilateral atrophic kidney-like tumors. Pathol Int. 2014;64:478-80. 
7. Berens S, Vogt P, Alkadhi H, Berger N, Moch H. Thyroid-like follicular carcinoma of the kidney: A separate tumor entity. Pathologe. 2014;35:83-87.

8. Herlitz L, Hes $\mathrm{O}$, Michal M, Tretiakova M, Reyes-Múgica M, Nguyen JK, Troxell ML, Przybycin CG, Magi-Galluzzi C, McKenney JK. “Atrophic Kidney”-like lesion: Clinicopathologic series of 8 cases supporting a benign entity distinct from thyroidlike follicular carcinoma. Am J Surg Pathol. 2018;42:1585-95.

9. Amin MB, Gupta R, Ondrej H, McKenney JK, Michal M, Young AN, Paner GP, Junker K, Epstein JI. Primary thyroidlike follicular carcinoma of the kidney: Report of 6 cases of a histologically distinctive adult renal epithelial neoplasm. Am J Surg Pathol. 2009;33:393-400.
10. Muscara MJ, Simper NB, Gandia E. Thyroid-like follicular carcinoma of the kidney. Int J Surg Pathol. 2017;25:73-7.

11. Amin MB, MacLennan GT, Gupta R, Grignon D, Paraf F, Vieillefond A, Paner GP, Stovsky M, Young AN, Srigley JR, Cheville JC. Tubulocystic carcinoma of the kidney: Clinicopathologic analysis of 31 cases of a distinctive rare subtype of renal cell carcinoma. Am J Surg Pathol. 2009;33:384-92. 